\title{
A Research on Newspaper Reading Habit in Japan: An Empirical Study
}

\author{
CHEN Chih-Chung ${ }^{1, \text { a }}$ \\ ${ }^{1}$ School of Journalism and Communication, Jinan University, Guangzhou 510632 China \\ achenzz03@gmail.com
}

Keywords: Japanese Newspapers, Newspaper Reading Habit, Rate of Reading, Reader Study

\begin{abstract}
Japan has a very blooming and powerful newspaper industry, with the top three largest newspapers in the world are all Japanese newspapers. Some domestic papers have discussed the traits and success factors of Japanese newspaper industry, but none of them have done any empirical study in Japan. This research used investigative method, gathering 208 questionnaires from Tokyo, in order to directly analyze and understand Japanese newspapers and readers. We found that a high percentage of Japanese have the habit of reading newspapers, and their loyalty toward newspapers are high. But on the other hand, younger people have much lower reading rate and loyalty than the elders, and this will be a big issue for Japanese newspapers. Some discussions and suggestions for the innovation of Japanese newspapers were also proposed.
\end{abstract}

\section{Introduction}

All manuscripts must be in English, also the table and figure texts, otherwise we cannot publish your paper.

Japan is an island country with a small population of only 127 million but still a $100 \%$ press power. The overall circulation of the Japanese newspapers is 69.1 million, following on the heels of China and India. However, according to 2010: Top 100 Daily Newspapers Worldwide (ranked by circulation) released by World Association of Newspapers and News Publishers, the top three newspapers were all Japanese. Among them, Yomiuri Shimbun ranked first again with a daily circulation of 10.019 million and it was also the only newspaper whose circulation exceeded 10 million. Japanese newspapers accounted for $50 \%$ in the top 10 newspapers worldwide (ranked by circulation).

Japanese newspapers, however, experienced a recession in the 21st century along with other countries in the face of challenges brought by new media and the financial tsunami erupting in 2007. The overall circulation decreased by 5.2 million in 2008 compared with that in 1998 . The per capita newspaper holdings declined as well. [1] What's more, Asahi Shimbun (ranking second in Japan) experienced its first deficit in 2009. Although faced with these difficulties, generally speaking, Japan was still one of the most successful press powers in the world.

The newspaper holdings of per thousand people in Japan reached 624 and that is to say almost everyone read newspapers. Japan Newspaper Publishers and Editors Association carried out a research into people's media exposure as well as media impression. It was found that $92.5 \%$ of the Japanese population would read newspapers, among which the proportion of subscribers reached $88 \%$ and $57.4 \%$ of the population read newspapers every day. [2] In addition, according to Japan's Comprehensive National Newspaper Survey (2003), newspapers were the most trustworthy media in the eyes of Japanese people: $79.9 \%$ of the population had confidence in newspapers while only $44.6 \%$ of the population believed in the television, and not to mention the even smaller proportions of people trusting the Internet, magazines and broadcasting (16\%, $11.5 \%$ and $11.4 \%$ respectively).

The Chinese scholars have made some achievements in the research into the Japanese newspaper industry. For instance, Liu Hong'en [3] argued that the high circulation of Japanese newspapers was bound up with its unique way of distribution-the monopoly system and delivering the newspapers directly to readers. In this way, readers could have quick and convenient access to the newspapers, resulting in the enhancement of reading motives. However, Liu Haigui [4] ascribed the prosperity of Japanese newspaper industry to the quick and intensive information, short but effective 
length of an article, as well as the convenient and unlocked distribution channel-all these were in accordance with the busy lifestyle of the Japanese.

But in general, the current domestic researches into the Japanese newspaper industry are all based on the second-hand documents, lacking the first-hand investigation data as well as the empirical analysis. Without the direct observation and investigation, it is hard to have a direct and clear understanding of the Japanese newspaper industry. Thus, this research starts from the perspective of the reading habits of Japanese readers and analyzes the reading behavior, trend and some problems emerging from the behavior as well as the trend through the investigation into an enormous number of samples. This is of certain academic and practical value.

\section{Methodology}

This research investigated into the reading habits of Japanese readers and their opinions on the newspapers by the survey study targeting at Tokyo-the city with the most intensive population and prosperous newspaper industry in Japan. It aims to discuss the trend of the Japanese newspaper industry and the problems within.

Instruments. Drawn upon the consumer behavior survey and the customer satisfaction survey in marketing, the questionnaire on "the intention of the newspaper reading habit" was designed. It consisted of two sections: the first section was made up of 14 questions while the second section contains six questions. The first section mainly aimed to find whether the interviewee has a habit of newspaper reading, whether he or she has experiences in reading newspapers, the frequency and time of reading, the types and contents of the newspapers they stick to, as well as whether there was a possibility to give up newspaper reading in the future. The second section was designed to have a understanding of the personal information-age, job and income-of the interviewee.

After the Chinese questionnaires were designed, two Chinese students studying in Tokyo assisted in translating them into Japanese. In order to ensure the accuracy of the contents, two Japanese students were asked to proofread and amend the questionnaires.

Sampling Method and Investigation Process. Three types of areas (the residential district, the business district and the cultural district) in Tokyo were investigated by quota sampling. The cultural district referred to the area where there were many schools, museums and galleries. The total number of questionnaires distributed was 270 and the recovery rate was 100\%. Among them, there were 208 valid questionnaires and the questionnaire effectiveness was $77 \%$. There were 80 valid questionnaires gathered in the residential district, 58 and 70 respectively in the business district and cultural district.

\section{Data Analysis}

Newspaper Reading Habits of Japanese. Among the 208 valid interviewees, 74\% of them had the habit of reading newspapers. Among these 154 interviewees who had the newspaper reading habit, there were $76 \%$ of them read newspapers every day and $7.1 \%$ of them read newspapers four to six days per week. Besides, there were $79.9 \%$ of the interviewees spending 2400 yen or above on buying the newspapers per month. This is linked to the high pricing of the newspapers in Japan. The retail prices of Yomiuri Shimbun and Asahi Shimbun are both 180 yen. What's more, there is nearly no discount for subscription. However, they still enjoy overwhelming popularity among readers and the relatively high pricing is also one of the factors guaranteeing that the Japanese newspapers can gain profits.

What is worth attention is that among the interviewees having the habit of reading newspapers, those who had read newspapers for more than ten years accounted for $69.5 \%$, and there were $7.1 \%$ of the interviewees having read newspapers for five to ten year. The percentage of those who kept the habit of newspaper reading for less than three years was only $17.5 \%$. What's more, when asked whether he or she would give up the habit of newspaper reading, $48.7 \%$ of the interviewees said "definitely not", and $22.7 \%$ of the interviewees said "not likely". The percentages of the interviewees who said "very likely" and "likely" totaled merely $14.9 \%$. In addition, when talking about "the frequency of changing the newspapers chosen”, 63.6\% of the interviewees said they had always 
sticked to the same newspapers. It can be seen obviously that the newspaper reading habit is ingrained in Japan. For many people, once they establish the habit of newspaper reading, they would stick to it and always read the same newspapers-sometimes the choice can even remain unchanged for a life time. This conforms to the national characters of Japanese-inertia and laying emphasis on the hierarchy. [5]

It is also conspicuous that when asked further about "the factors leading you to give up the habit of newspaper reading", $64.6 \%$ of the interviewees chose "the impact of the Internet and the cellphone media". This figure is followed by the percentages (both 17.7\%) of the interviewees who chose "the impact of the TV and the broadcasting" as well as "the decline of the quality of the newspapers". This shows that the influence of the new media cannot be belittled even though in Japan where the habit of newspaper reading is ingrained.

Content Preferences and Selection Criteria of Japanese's Newspaper Reading. Among the 154 interviewees who had the habit of newspaper reading, $71.4 \%$ of them would read political/social news and $43.5 \%$ of them would read consumption/entertainment news. The percentage of the people reading advertisements accounted for $13.6 \%$. It cannot be ignored that there were $66.2 \%$ of the interviewees reading newspapers for less than one hour per day. The proportion of the people who read newspapers for one to two hours accounted for 29.2\%. These two figures totaled more than $95 \%$. This goes hand in hand with the busy lifestyle of the Japanese people-newspapers must let the readers get the most full-scale information within the shortest duration. Liu Haigui mentioned that there were at least fifteen pieces of news on each layout in order to disseminate sufficient and intensive information, making it convenient for readers to have a scan; thus the average duration within which Japanese readers spent on reading newspapers per day is only fifteen minutes. This reflects the principle of being effective and concise.

Besides, for the factors affecting the newspaper choosing, $40.9 \%$ of the interviewees regarded "the content" as the most important one. $37.6 \%$ of the interviewees chose "the credibility and the fame". $27.3 \%$ of the interviewees emphasized most on "the headlines and the formats". $21.4 \%$ of the interviewees thought that the "the number of pages" was the most crucial factor. Only $5.8 \%$ of the interviewees gave priority to the price, and $9.7 \%$ of the interviewees took gifts and convenience into consideration. "Content is king” is embodied thoroughly in the Japanese newspaper market.

Crosstab Analysis. In the analysis of the habit of newspaper reading mentioned above, it can be seen that the proportion of the Japanese having the habit of newspaper reading and the loyalty towards certain newspapers are high. Meanwhile, the experience of reading newspapers has existed for a long time. All these as a whole happened to coincide with the image of Japan-a press power. However, some underlying problems were exposed in the crosstab analysis of the personal information of the interviewees and their reading habits.

First of all, we used the crosstab analysis to investigate the age of the readers and their reading habits (whether they had the habit of reading newspapers, the frequency of newspaper reading, whether they might give up reading newspapers in the next ten years and the possible reasons for the abandonment) with SPSS 14.0 as the tool of calculation. Meanwhile, Chi-square analysis is used to test whether the differences in the parameters of different groups had the statistical significance.

Table 1 reflects that there is a correlation between the age and the habit of newspaper reading. It can be observed that the proportion of people having the habit of newspaper reading goes higher as the age grows. There are $97 \%$ of the people above 66 years old having the habit of newspaper reading. However, there are only $40 \%$ of the interviewees below 18 years old having the habit of newspaper reading. The proportion of people aged between 18and 25 having the habit of newspaper reading is $61.9 \%$. The result of the Chi-square test demonstrates that the differences between these age groups have met the requirement of the statistical significance. 
Table1 the crosstab analysis and the Chi-square test of the age and the habit of newspaper reading

\begin{tabular}{|l|l|l|l|l|l|l|l|l|l|}
\hline & \multicolumn{7}{|c|}{ The age groups of the interviewees } & Sum \\
\hline $\begin{array}{l}\text { Have/Have } \\
\text { Not } \\
\text { newspaper } \\
\begin{array}{l}\text { reading } \\
\text { habbit }\end{array}\end{array}$ & Yes & $40 \%$ & $61.9 \%$ & $54.5 \%$ & $87.5 \%$ & $76.2 \%$ & $96.8 \%$ & $97 \%$ & $74 \%$ \\
\cline { 2 - 10 } & No & $60 \%$ & $38.1 \%$ & $45.5 \%$ & $14.3 \%$ & $23.8 \%$ & $3.2 \%$ & $3 \%$ & $26 \%$ \\
\hline
\end{tabular}

It can be seen from Table 2 that among the groups having the habit of newspaper reading, there is also a correlation between the age of the interviewees and the frequency of newspaper reading per week. The frequency declines as the age goes down. Only $25 \%$ of the interviewees below 18 years old read newspapers every day. 30.8\% of the interviewees aged between 18 and 25 have the habit of reading newspapers every day. In contrast, the percentages of the interviewees above 36 years old reading newspapers every day all exceed 95\%. The result of the Chi-square test shows that the differences between these age groups have met the requirement of the statistical significance.

Table2 the crosstab of the age and the frequency of newspaper reading per week

\begin{tabular}{|c|c|c|c|c|c|c|c|c|c|}
\hline & \multicolumn{8}{|c|}{ The age groups of the interviewees } & \multirow[t]{2}{*}{ Sum } \\
\hline \multirow{4}{*}{$\begin{array}{l}\text { Newspa } \\
\text { per } \\
\text { reading } \\
\text { per } \\
\text { week }\end{array}$} & & $<18$ & $18-25$ & $26-35$ & $36-45$ & $46-55$ & $56-65$ & $>66$ & \\
\hline & $\begin{array}{l}1-3 \\
\text { times }\end{array}$ & $\begin{array}{l}62.5 \\
\%\end{array}$ & $53.8 \%$ & $27.8 \%$ & $4.2 \%$ & $0 \%$ & $0 \%$ & $3.1 \%$ & $17 \%$ \\
\hline & $\begin{array}{l}4-6 \\
\text { times }\end{array}$ & $\begin{array}{l}12.5 \\
\%\end{array}$ & $15.4 \%$ & $27.8 \%$ & $0 \%$ & $0 \%$ & $3.3 \%$ & $0 \%$ & $7 \%$ \\
\hline & 7 times & $25 \%$ & $30.8 \%$ & $44.4 \%$ & $95.8 \%$ & $100 \%$ & $96.7 \%$ & $96.9 \%$ & $76 \%$ \\
\hline
\end{tabular}

Table 3 illustrates that the possibility for the interviewees to give up the habit of newspaper reading is connected with the age. The younger the interviewees are, the more likely that that they would give up this habit. Only $42.3 \%$ of the interviewees aged between 18 and 25 chose "not very likely" or "definitely not". However, the percentage of the interviewees above 36 years old having the same options reaches $70 \%$ or above. The proportion of the interviewees above 66 years old rises to $87.5 \%$. The result of the Chi-square test shows that the differences between these age groups have met the requirement of the statistical significance.

Table3 the crosstab analysis of the age and the possibility of giving up the habit of newspaper reading in the next ten years

\begin{tabular}{|c|c|c|c|c|c|c|c|c|c|}
\hline & \multicolumn{8}{|c|}{ The age groups of the interviewees } & \multirow[t]{2}{*}{ Sum } \\
\hline \multirow{6}{*}{$\begin{array}{l}\text { The } \\
\text { possibilit } \\
\text { y of } \\
\text { giving up } \\
\text { reading } \\
\text { newspap } \\
\text { er }\end{array}$} & & $<18$ & $18-25$ & $26-35$ & $36-45$ & $46-55$ & $56-65$ & $>66$ & \\
\hline & $\begin{array}{l}\text { Very } \\
\text { likely }\end{array}$ & $0 \%$ & $15.4 \%$ & $5.6 \%$ & $8.3 \%$ & $0 \%$ & $10 \%$ & $6.3 \%$ & $8 \%$ \\
\hline & $\begin{array}{l}\text { Likel } \\
\text { y }\end{array}$ & $0 \%$ & $15.4 \%$ & $5.6 \%$ & $12.5 \%$ & $0 \%$ & $6.7 \%$ & $3.1 \%$ & $7 \%$ \\
\hline & $\begin{array}{l}\text { Don't } \\
\text { know }\end{array}$ & $25 \%$ & $26.9 \%$ & $16.7 \%$ & $8.3 \%$ & $12.5 \%$ & $13.3 \%$ & $3.1 \%$ & $14 \%$ \\
\hline & $\begin{array}{l}\text { Not } \\
\text { likely }\end{array}$ & $25 \%$ & $15.4 \%$ & $55.6 \%$ & $33.3 \%$ & $18.8 \%$ & $10 \%$ & $15.6 \%$ & $23 \%$ \\
\hline & $\begin{array}{l}\text { Not at } \\
\text { all }\end{array}$ & $50 \%$ & $26.9 \%$ & $16.7 \%$ & $37.5 \%$ & $68.8 \%$ & $60 \%$ & $71.9 \%$ & $48 \%$ \\
\hline
\end{tabular}

The result of the Chi-square test: Chi-square Value=43.40, Degree of Freedom=24, $\mathrm{P}$ Value $<0.01$ 
Above all, the conclusion of the crosstab analysis is as follows: although the overall proportion of people reading newspapers is large in Japan and the loyalty towards certain newspapers is quite high, the younger the groups are, the less enthusiastic they feel towards newspaper reading. Thus, the proportion of young people reading newspapers is small. Even if the young have the habit of newspaper reading, the possibility for them to give up this habit in the future is much higher than that for the elder people. This is an underlying worry in the Japanese newspaper industry.

\section{Conclusions and Suggestions}

This research investigated the newspaper reading habit and behavior of the Japanese people by the survey study and the field distribution of questionnaires in Tokyo.

This habit of newspaper reading is bound up with the national cultural traits of the Japanese. Geert Hofstede [6], the famous scholar in the field of cross-cultural studies, found that Japan scored extremely highly in Uncertainty Avoidance and Long Term Orientation (92 and 80 respectively) by the quantitative research and the comparative analysis targeting at the cultures of 93 countries or regions. This reveals that the Japanese hate risks and uncertainties (Uncertainty Avoidance). Besides, they focus on the future rather than the present; value thrift and persistence (Long Term Orientation). Their loyalty towards something they are familiar to or fond of is very high. I means they keep doing the same things for decades or even a life time, and the habit would be passed on to the next generation. This is sure to be the impetus for the antique newspapers to thrive in Japan- a modernized society with a high level of informatization.

What's more, the Japanese are pragmatists. They like things that are simple and practical. The Japanese newspapers are informative, practical, concise and forceful-in accordance with the characteristics of the Japanese people.

But after the further crosstab analysis, it was observed that there were significant differences in the newspaper reading habits of different age groups and occupations. The younger the groups are, the smaller proportions of readers in these groups are, and the more likely that they would give up newspaper reading in the future. When the aged loyal readers get elder, whether the younger generation can maintain the high rate of newspaper reading is an alarming question. In fact, there is a remarkable difference in the cultures and lifestyles of the young and the old in Japan [7]. The young prefer consumption and entertainment, value individuality and differentiation [8]. Such a large gap of values between generations is a huge challenge to the media industry, including newspapers, and other sectors.

According to the combination of the trend as well as the problems emerging during the data analysis and the reform of the Japanese newspaper industry currently, some suggestions are raised for the Chinese newspaper industry to follow:

The content is still the core of the competitiveness of the newspaper industry: Japanese newspapers are informative and concise in the content. It is rare to see sensational headlines or pictures that intend to intrigue readers on the Japanese newspapers. Besides, the Japanese newspaper industry seldom gain the market share by reducing prices or giving out gifts. According to this research, "the content" is the primary factor (accounting for $40.9 \%$ ) that makes the Japanese to decide which newspaper to read. The following factor is "the credibility and the fame" (accounting for $37.6 \%$ ). All types of advertisements and promotion might boost the fame and sales in a short period of time. But only the improvement of the content can maintain the newspaper's long-term competitiveness

Intensive news information benefits the readers: all the newspapers now are face with the challenge brought by the new media, among which the Internet and the cellphones gain the leading position because of their convenience, low costs and richness in information. However, the superfluous and rough information on the Internet enhanced the difficulty for the readers to find what they need. In this case, if the newspapers can disseminate the most important information to the readers within the shortest duration concisely and intensively, they will maintain the superiority even though in the information society. As is discovered in the investigation, $66.2 \%$ of the Japanese 
readers spend less than one hour on the newspapers per day. Besides, some data revealed that the duration of newspaper reading in Japan is only 15 minutes.

Stimulating the young's will to read newspapers by journalism education: the crosstab analysis demonstrates that the proportion of young readers in Japan is small and they do not read as much as the old. Besides, their loyalty is not high. Particularly, quite a number of students do not have the willing or the habit of reading newspapers. If the young are indulged with the decreasing rate of newspaper reading, the Japanese newspaper industry is sure to experience the crisis some day. Therefore, Japan has promoted "Newspaper in Education" (NIE, launched by New York Times in 1930 with now 52 participating countries) since 1985. This program offers schools with newspapers for free. These newspapers would be used as accessory materials in teaching to enhance the news literacy and cultivate the habit of newspaper reading of the students. $1 \%$ of the schools (including primary schools, high schools and universities) around Japan have now participated in NIE. The approach of blending newspapers with the school education and fostering the students' ability to read and understand news at a young age can be followed by us as well. Meanwhile, this approach can cultivate future newspaper readers as well.

Above all, this research summarized a number of key factors leading the Japanese newspaper industry to thrive in terms of the reading habit, loyalty and what makes readers to choose certain newspapers on the basis of the empirical study in Tokyo. The insight crosstab analysis discovered the underlying problems of the prosperity of the Japaneses newspaper industry. The exposure of these problems as well as the understanding of the reform of the Japanese newspaper industry is valuable for the Chinese newspaper industry.

\section{Acknowledgments}

This study is funded by the project of the Guangdong Province's 12th Five-Year Plan in Philosophy and Social Science, the study of Media Groups' Organizational Culture and Organizational Performance (Grant No. GD11YXW01).

\section{References}

[1] J. Han: The Struggle and Transformation of Japanese Newspapers in New Media Era. Contemporary Communication, 2009(4). (in Chinese)

[2] M. Wei: Deciphering Japanese Newspapers’ High Circulation. News Journalist, 2006(11). (in Chinese)

[3] H. Liu: Unique Circulating Ways of Japanese Newspapers. Chinese News Journal, 2001(5). (in Chinese)

[4] H. Liu: Behind the Blossom of Japanese Newspapers. Journalistic University, 1998(4). (in Chinese)

[5] Z. Li: Some Traits of Japanese Nationality. Japanese Learning and Research, 2007(5). (in Chinese)

[6] G. Hofstede: The National Culture: Japan. http://geert-hofstede.com/website/japan.html

[7] J. Shi: Analyzing Japanese Youth's Value Changes from the Perspective of Behaviors. Japanese Knowledge, 2002(10). (in Chinese)

[8] S. Qian: Cultural Traits of Japanese Youth. Chinese Youth Research, 1991(1). (in Chinese) 